Original paper

\title{
Role of post-settlement mortality in the establishment of Acropora reef slope zonation in Ishigaki Island, Japan
}

\author{
Go SUZUKI ${ }^{1, *}$, Takeshi HAYASHIBARA ${ }^{1}$, and Haruhiko TOYOHARA ${ }^{2}$ \\ ${ }^{1}$ Ishigaki Tropical Station of Seikai National Fisheries Research Institute, Okinawa 907-0451, Japan \\ ${ }^{2}$ Division of Applied Biosciences, Graduate School of Agriculture, Kyoto University, Kyoto 606-8502, Japan \\ * Corresponding author: G. Suzuki \\ E-mail: gosuzu@fra.affrc.go.jp
}

Communicated by Masayuki Hatta (Biology and Ecology Editor)

\begin{abstract}
The relative contributions of larval recruitment and post-settlement mortality to the establishment of the zonation of Acropora communities, a dominant group in reef corals, remain unknown. Our field research revealed that the relative abundances of juveniles between two morphological categories of acroporid corals were different on shallow and deep slopes: tabular species dominated in shallow waters $(1.5-2.5 \mathrm{~m})$, whereas arborescent species dominated in deep waters $(5.5-11 \mathrm{~m})$. These abundances were consistent with the distributional patterns of the adults, suggesting that the zonation structure is formed during the initial life stages of settlement and early postsettlement periods. To determine to what extent Acropora zonation is determined by depth-related differences in initial mortality among species, a transplant experiment using artificially settled corals (10 days after settlement) of four dominant species (the shallow-dominants Acropora digitifera and $A$. selago and the deep-dominants $A$. muricata and A. tenuis) was performed at four depths (1.5, $2.5,5.5$, and $11 \mathrm{~m}$ ). Survivorship of all four species was lower at $5.5 \mathrm{~m}$ than the other depths and that the survival rate of $A$. muricata was much higher than that of other species at all depths. However, there was no speciesspecific survival related to adaptation to a particular habitat (i.e., depth), implying that Acropora spats do not possess species-specific tolerance for the environmental
\end{abstract}

stresses of their own particular habitat, at least during the first 6 months after settlement. Post-settlement survival rate during this period is therefore not a major factor in forming the vertical zonation pattern of these Acropora species in subtropical reefs around Japan.

Keywords Acropora, initial mortality, vertical zonation, transplantation, light environment

\section{Introduction}

Acroporid corals constitute one of the most diverse and abundant scleractinian coral groups in the Indo-Pacific region and are a major component of the vertical zonation of most reef slope assemblages (Wallace 1999). The diversity of colony morphology in Acropora species is extremely high. However, this diversity can be classified into a number of morphological groups, including indeterminate arborescent forms that grow upward (hereafter called 'arborescent' forms) and determinate plate or dome shapes that grow mostly horizontally (hereafter called 'tabular' forms including digitate and corymbose forms). Many species that form tabular colonies inhabit the upper reef slopes, whereas the arborescent species abound in the 
middle or lower slopes and lagoons, but there is no distinct boundary between the distributions of the two forms (Done 1982; Veron 2000). The relationship between physical factors and colony forms is believed to effect their respective depth zonation as follows their distributional range (Sheppard 1982; Adjeroud 1997). In general, the tabular forms are more dominant in places where wave exposure is high in contrast arborescent forms, which are more fragile, dominate in calmer areas of the reef (e.g. Suzuki et al. 2008). Accordingly, a life stage later than the morphological differentiation of colony form (i.e., more than 2 or 3 years after settlement) is likely to be important for the establishment of acroporid zonation. However, the role of early life-history stages in the structuring of Acropora communities has not previously been examined (but see Wallace 1985).

The initial life stage processes of settlement behavior and survival after settlement are largely unknown in Acropora corals. Using both mitochondrial and nuclear genetic markers, Suzuki et al. (2008) showed that the species composition of new recruits (collected within 10 days after settlement) of Acropora differed among three different depths (2.5 to $11 \mathrm{~m}$ ) on a reef slope, and the recruitment patterns reflected the density pattern of adult conspecifics. That study strongly suggested the existence of species-specific selective settlement patterns in Acropora corals. Moreover, it has been suggested that larval settlement plays a greater role than post-settlement survival in maintaining the vertical zonation of reef corals other than Acropora (Babcock and Mundy 1996; Mundy and Babcock 1998, 2000; Baird et al. 2003). Considering these results, selective settlement behavior is likely to be as important as post-settlement processes even in the establishment of depth zonation involving closely related and sympatric species such as Acropora corals.

To assess the importance of post-settlement processes, it is necessary to determine whether initial survival differs among species or colony types. Mortality during the first few months after settlement is generally very high in benthic marine invertebrates, including corals (Gosselin and Qian 1997; Mundy and Babcock 2000; Wilson and Harrison 2005). To date, however, there is little information for Acropora corals regarding the stage in the life history during which a difference in mortality between shallow- and deep-habitat species can be observed. This difference may increase gradually throughout the growing period, or increase drastically at a specific stage, such as immediately after settlement; or it may never exist at all. To test the hypothesis that the vertical zonation of Acropora corals is established before the corals complete the formation of their colony shapes, initially the density of juvenile colonies of each growth form was surveyed at different depths of a reef slope. Subsequently, to compare early post-settlement mortality among species with different colony shapes, a transplantation experiment was conducted in the field. Because it is impossible (Babcock et al. 2003) to morphologically distinguish species of recently settled corals (hereafter called recruits), artificially settled spats that reared from known adults (hereafter called ASS) were used in the experiment. Moreover, to examine environmental effects on ASS mortality, the light intensity and the neighboring sessile fauna were recorded. This is because light and sessile fauna seem to relate strongly to depth on reef slopes (Baird et al. 2003), although many other factors such as flow, sedimentation, herbivore grazing, and competing benthic organisms affect ASS survival in general. This work is the counterpart to a study that explored the existence of selective settlement in Acropora larvae (Suzuki et al. 2008). From the results of these two studies, it is attempted to assess the role of these different processes in establishing vertical zonation in Acropora.

\section{Materials and methods}

\section{Study area}

On the northern shoreline at Ishigaki Island $\left(24^{\circ} 27^{\prime} \mathrm{N}\right.$, $124^{\circ} 12^{\prime}$ E, see Fig. 1 in Suzuki et al. 2008), reef flats with a width of 100-200 m and reef slopes with a depth of 20$30 \mathrm{~m}$ have developed. Five depths were selected at Tomino Reef (at four depths: reef crest, $1.5 \mathrm{~m}$; shallow zone, $2.5 \mathrm{~m}$; middle zone, $5.5 \mathrm{~m}$; and deep zone, $11 \mathrm{~m}$ ) and Urasoko Reef (depth $1.5 \mathrm{~m}$ ) as research stations. The coral coverage at each depth was surveyed in 2004 (Suzuki et al. 2008), and the results showed that three corymbose- or tableshaped species (A. hyacinthus Dana, 1846, A. digitifera Dana, 1846, and A. nasuta Dana, 1846) were dominant in the shallow zone $(1.5-2.5 \mathrm{~m})$. In this study, the colony 
type referred to as tabular also includes some colony morphologies that have some horizontal growth across the substratum, such as corymbose and digitate. Two arborescent species (A. muricata Linnaeus, 1758 and $A$. intermedia Brook, 1891) and a corymbose-shaped species (A. tenuis Dana, 1846) were mainly observed at the middle and deep depths (5.5 and $11 \mathrm{~m}$, respectively). At Urasoko Reef, two corymbose-shaped species, A. selago Studer, 1878 and $A$. nasuta, were abundant. Light intensity, as one of the key factors that changes in relation to depth and affects the survivorship of corals, was measured at $10 \mathrm{~min}$ intervals for 1 week at each depth during June 2005 using a compact light photon meter (MDS-MkV/L; Alec Electronics Co., Ltd).

\section{Distribution of Acropora juveniles}

To estimate Acropora juvenile density, two belt transects $(0.5 \times 5 \mathrm{~m})$ were used at each depth of Tomino Reef. On each transect, 10 quadrats $(0.5 \times 0.5 \mathrm{~m})$ were placed and the number of colonies with a diameter of less than $10 \mathrm{~cm}$ was counted in June 2005. If possible, the species or the colony shape (tabular or arborescent) was identified. These corals were classified into three size classes: 0-2 cm, 2-5 cm, and 5-10 cm, as corresponding to approximately 1, 2-3, 4-5 years old, respectively (Hayashibara et al. 2004b). However, neither species nor colony shape could be identified in corals with a diameter of less than $2 \mathrm{~cm}$. Although the largest size class $(5-10 \mathrm{~cm})$ might have encompassed some mature colonies (Harrison and Wallace 1990), we defined them as 'juvenile' because most Acropora corals in this size did not complete the formation of their colony shapes.

\section{Transplant experiment}

Four dominant species (A. digitifera, A. tenuis, A. muricata, and $A$. selago) were selected for transplants, and 6-10 gravid colonies of each species were collected in May 2004. To acquire larvae at the same time in the laboratory, spawning was induced using $\mathrm{H}_{2} \mathrm{O}_{2}$ (Hayashibara et al. 2004a). Almost all corals spawned on the same night, and the egg-sperm bundles were collected and inseminated. The fertilized eggs were reared in $100 \mathrm{~L}$ tanks for 4 days, and the larvae were then settled on artificial plates (unglazed tiles, $4.5 \times 4.5 \times 0.7 \mathrm{~cm}$ ). The plates had been conditioned in the sea (at depth $4 \mathrm{~m}$ ) for 5 months before the experiment because Acropora larvae rarely settle on new tiles (e.g. Baird et al. 2003). After 3 or 4 days, the number of ASSs on the plate was counted. The positions of settlement of all ASSs were mapped in order to differentiate them from the wild recruits that were expected to settle on the plates after setting in the field.

Ten days after settlement, six pairs of (replicate) plates for each species were transferred from the rearing tanks to the four depths at two reefs $(2.5,5.5$, and $11 \mathrm{~m}$ at Tomino Reef and $1.5 \mathrm{~m}$ at Urasoko Reef) $(6 \times 4$ species $\times 4$ depths $=96$ pairs of plates). The $1.5 \mathrm{~m}$ depth on the crest of Tomino Reef was excluded from this experiment since the plates were destroyed by wave action in a preliminary test. These plates were attached to a concrete block, which was fixed on the reef substratum, using stainless steel bolts that secured the paired plates (one plate upwardfacing and a shaded downward-facing plate). To avoid pseudo-replication, the pairs from a single species were attached randomly on the block without neighboring plates being of the same species (Fig. 1). All plates were retrieved for the first time in June (38 d after transfer), then in July (64 d), September (114 d), and December (222 d). At the time of each retrieval, the plates were photographed to record the sessile organisms, and examined under a stereo microscope to determine the number of surviving corals and their positions; the plates were then replaced in the same position on the block. To compare the relative light intensities on the surfaces of upwardand downward-facing plates, a diver measured light photon density for 5 minutes at $1 \mathrm{sec}$ intervals at each depth before noon using a self-recording light photon

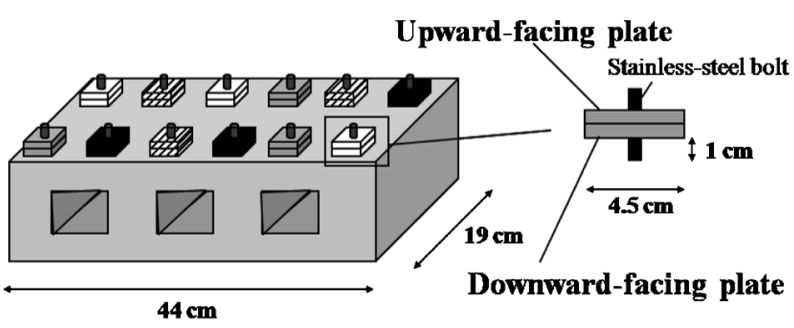

Fig. 1 Schematic illustration of settlement plates attached on the sea bottom in the transplant experiment. Pairs of upward- and downward-facing plates were fixed on concrete blocks. Different colors (and pattern) of plates represent that the ASSs were derived from different species 
meter (ALW-CMP; Alec Electronics Co., Ltd) in the upward and downward directions ( $1 \mathrm{~cm}$ above the block).

\section{Statistical analysis}

The densities of juvenile corals were compared among four different depths on Tomino Reef in each colony form (tabular and arborescent) using one-way analysis of variance (ANOVA) to test the null hypothesis of equivalent densities at different depths. If the null hypothesis was rejected, multiple comparisons of juvenile density among depths were performed by Bonferroni t-test. For the result of transplant experiment, survival rates of each species (A. digitifera, A. muricata, A. selago, and A. tenuis) were compared among different depths using Kaplan-Meier survival curve with log-rank test. Multiple comparisons were performed by Holm-Sidak method. In addition, because the number of initial ASSs differed among plates and species, Poisson generalized linear model (GLM) analysis was carried out between the number of initial and dead ASSs (initial density model) to determine whether density-dependent mortality was present using statistical software package R version 2.3.1. Significant difference of the deviance between null and initial density model was calculated by chi-square test. Algal coverage on the settlement plate was specified using the function of selecting a particular color area in software Photoshop 7.0.1 and calculated using Scion Image 4.0.3 and then compared among depths by ANOVA and Bonferroni t-test. Light intensity on the downward-facing plate was averaged in each 10 seconds (10 measurements) with $10 \mathrm{sec}$ intervals and total 16 averaged measurements were obtained. Light intensity was compared among depths using Kruskal and Wallis test because the variance was not homogenous and statistical significance $(p<0.05)$ was further examined by Scheffe's test for multiple comparison. All statistical analyses except the GLM analysis were performed using software SigmaStat version 3.0.1.

\section{Results}

\section{Distribution of juvenile corals}

A total of 306 juveniles of Acropora corals was counted in the field with a density of approximately 10 -fold higher
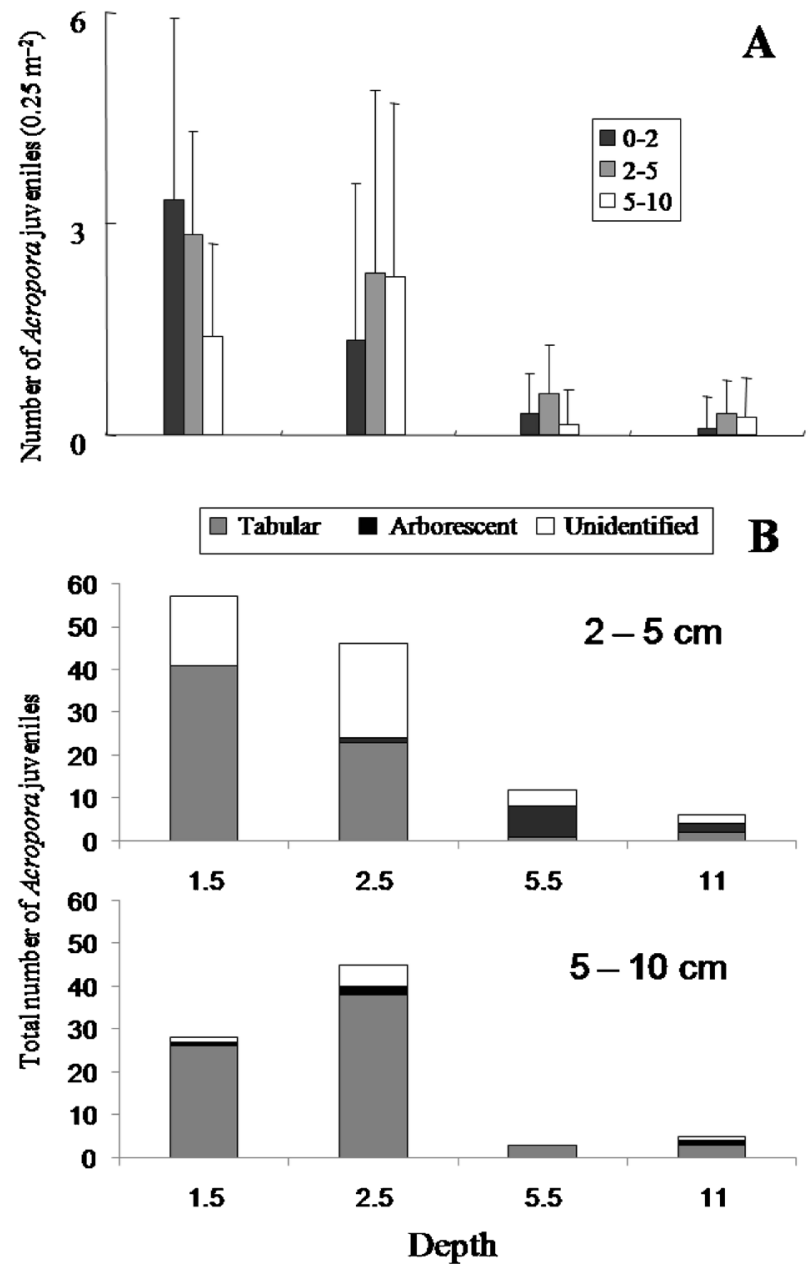

Fig. 2 Acropora juveniles. A) Average number of juveniles per $0.25 \mathrm{~m}^{2}$ quadrat $(\mathrm{N}=20)$ at four depths at Tomino Reef for three size categories (colony diameter 0-2, 2-5, 5-10 $\mathrm{cm}$ ). Error bars mean standard deviations. B) Total number of tabular and arborescent colony types in the middle size $(2-5 \mathrm{~cm}$, upper graph) and the large size $(5-10 \mathrm{~cm}$, bottom graph) groups. The number of individuals whose colony type could not be determined is shown as "unidentified"

at the shallow depths $(1.5$ and $2.5 \mathrm{~m})$ than at the deep depths (5.5 and $11 \mathrm{~m}$ ) (Fig. 2A, Bonferroni t-test, $p<0.01$ ). There were no differences in density among the three size classes; colony diameters $0-2,2-5$, and 5-10 $\mathrm{cm}$. Although most colonies of the smallest size class $(0-2 \mathrm{~cm})$ could not be identified, among those of the middle size class (2$5 \mathrm{~cm}$ ), tabular colonies were dominant at the shallow depths, whereas only a few tabular colonies were found at the deep depths (Fig. 2B). The number of arborescent colonies was small at any depths, so the proportions of arborescent colonies were larger at the deep depths than 
the shallow depths. In addition, the occurrence ratios between tabular and arborescent colonies did not differ for the two size classes at all depths except the $5.5 \mathrm{~m}$ (Fig. 2B).

\section{Post-settlement survival}

The number (mean $\pm \mathrm{SD}$ ) of initial ASSs per plate was 31.2 \pm 15.7 for Acropora digitifera (748 ASSs in total), $32.7 \pm 15.2$ for $A$. tenuis (771 ASSs in total), 10.6 44.9 for A. muricata (248 ASSs in total), and $41.8 \pm 28.4$ for A. selago (1017 ASSs in total). The lower density for $A$. muricata did not result from a lower settlement rate but lower number of obtained larvae than in the other species. Because more than $90 \%$ of specimens disappeared from most of the upward-facing plates by $38 \mathrm{~d}$ after transfer, the survival rate was analyzed only on the specimens on the downward-facing plates. The survival curves of Acropora ASSs through the experimental periods (38-222 d after settlement) were different among depths in all species (Fig. 3). In the first period, lower survivals were observed at a depth of $5.5 \mathrm{~m}(26.6 \pm 24.3 \%$, mean $\pm \mathrm{SD})$ than at the two shallower depths (approximately 50\%) in all species (especially in $A$. digitifera) but $A$. selago. However, no species specific trends in survival were apparent at any certain depth. At the last retrieval (114-222 d), more than 6 months after transfer, all corals had 100\% mortality except those at the two shallower depths: $99.7 \%$ at the 2.5 $\mathrm{m}$ at Tomino Reef and $98.9 \%$ at the $1.5 \mathrm{~m}$ at Urasoko Reef; the differences in survival rates among depths were not significant (ANOVA, $p>0.05$ ). The higher survival rate of $A$. muricata was maintained during first two periods (38-64 d). The deviance in the initial density model was significantly lower than the null model in GLM analysis (chi-square test, $p<0.01$ ), hence, the cause of the high survival rates of $A$. muricata is highly probable to be due to the low number of initial ASSs on each plate.

No visible differences were observed among the sessile organisms on the plates at different depths throughout the experimental periods, except the bleaching of red coralline algae on the downward-facing plates at the deep depth $(11 \mathrm{~m})$ and the high percentage cover of filamentous algae on the upward-facing plates of the middle slope $(5.5 \mathrm{~m})$ at Tomino Reef (data not shown). Most of the filamentous algae were found inside of damselfish territories, so this difference of algal composition did not depend on the depth but habitat.

\section{Light environment}

The intensity of light on the upward-facing plates was greatest at $1.5 \mathrm{~m}$ depth on the reef slope and gradually attenuated with depth; it was $92 \%$ at $2.5 \mathrm{~m} ; 58 \%$ at $5.5 \mathrm{~m}$; and $42 \%$ at $11 \mathrm{~m}$ in the cumulative amount of light photon (Fig. 4A). At the $1.5 \mathrm{~m}$ depth at Urasoko Reef, it was reduced to $69 \%$ of the highest intensity received at Tomino

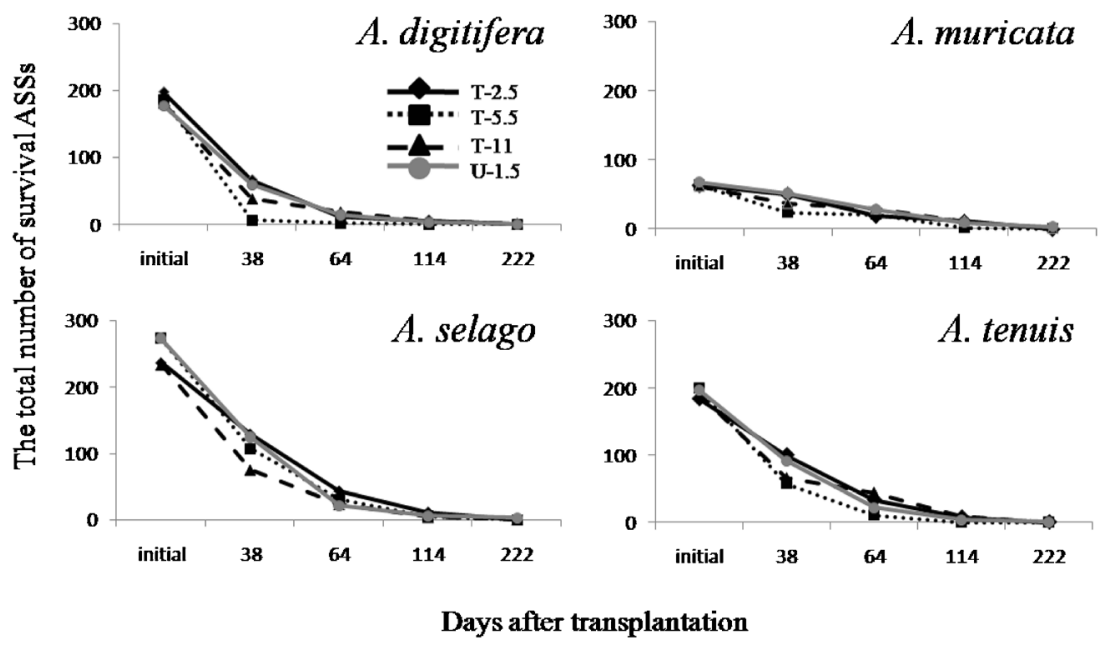

Fig. 3 The number of survival ASSs of Acropora spp. (downward-facing plates) during four retrieval periods $(38,64,114,222 \mathrm{~d}$ after settlement) at three depths at Tomino Reef (T-2.5, 5,5 and $11 \mathrm{~m})$ and $1.5 \mathrm{~m}$ depth at Urasoko Reef (U-1.5) 


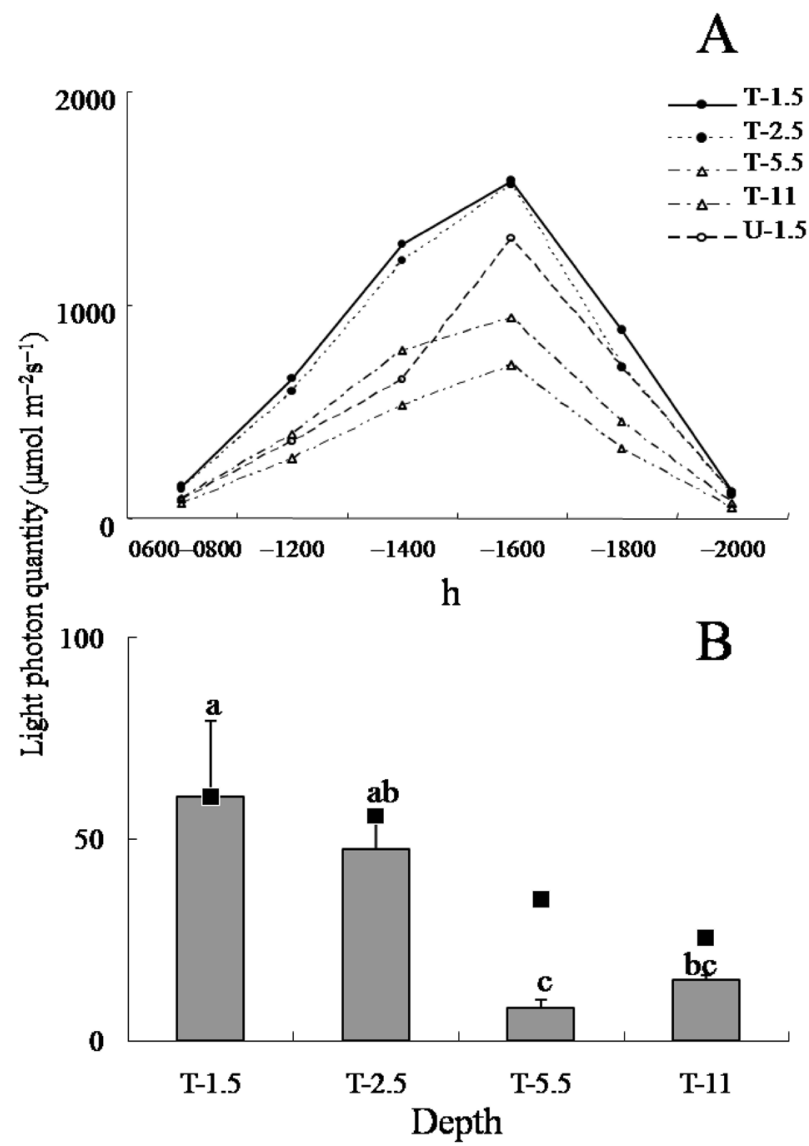

Fig. 4 Light intensity on the reef slope at different depths

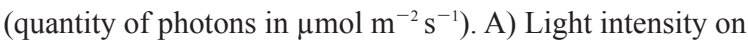
the upper side of the plates is the average of measurements on three clear days in June 2005. B) Light intensity on the lower side is the average of measurements for $5 \mathrm{~min}$ at noon of a clear day in June 2006. Each point on the bar represents expected value from the upper side intensity. Kruskal and Wallis test and Scheffe's test were used to determine the significant differences in the light intensity (denoted by lower-case letters on the bars, $p<0.05$ ). Site designations are as in Figure 3

Reef because of high turbidity. The light intensity on the lower side of the settlement plates was $5.4 \%$ of the light intensity on the upper side at the $1.5 \mathrm{~m}$ depth, $4.2 \%$ at $2.5 \mathrm{~m}, 0.7 \%$ at $5.5 \mathrm{~m}$, and $1.3 \%$ at $11 \mathrm{~m}$ (Fig. 4B). These reduction rates were lower than those expected from the intensity on the upper side, especially at the $5.5 \mathrm{~m}$ depth; $5.4 \%$ at $1.5 \mathrm{~m} ; 5.0 \%$ at $2.5 \mathrm{~m} ; 3.1 \%$ at $5.5 \mathrm{~m}, 2.3 \%$ at $11 \mathrm{~m}$. The difference in light intensity between the shallow (up to $2.5 \mathrm{~m}$ ) and deep (more than $5.5 \mathrm{~m}$ ) depths was significant (Scheffe's test, $p<0.05$ ).

\section{Discussion}

\section{Role of early post-settlement mortality in establishing} Acropora zonation

The depth-related zonation of Acropora species at Tomino Reef was evident in adult populations (Suzuki et al. 2008). This study found that the distribution of Acropora juveniles was concentrated in shallow waters, and the number of juveniles decreased as depth increased (Fig. 2A). A large number of tabular-type colonies occurred at shallow depths, although the tendency was not clear in deep waters because of too few juveniles (Fig. 2B). Importantly, a distribution tendency depending on the colony type was observed in the middle size class $(2-5 \mathrm{~cm})$ of juveniles. This size class was estimated as being less than 3 years old by comparison with the growth records of conspecific colonies settled on artificial reefs (Hayashibara et al. 2004b). Thus, the zonation structures of Acropora are considered to be formed within 3 years after settlement.

These results suggest that natural selection in these corals occurs before a determinate shape is established. Accordingly, it is possible that selection pressures such as wave promoted the adaptive behaviors of corals in their earlier life stages. That is, the larvae may settle selectively at a suitable depth or the early post-settlement mortality of juveniles may differ among species or colony types at each depth. The fact that occurrence ratios between the colony types were not different in middle and large size classes at any depths also supports the importance of early life stages (i.e. within 2 years after settlement) in Acropora corals.

It is well known that the survival rate of new recruits in the early post-settlement period is low, mainly because of predation, competition and sedimentation (Bak and Engel 1979; Sato 1985; Maida et al. 1994; Dunstan and Johnson 1998). Thus, it was expected that there are particular factors that strongly influence species-specific survival or mortality at this stage. To test this hypothesis, the survival rates of Acropora ASSs were compared at three different depths on the reef slope habitat during the initial 6 months after settlement. However, the initial survival rate of ASSs was not significantly different among the depth and species 
that had different colony shapes, but it depended on initial density on the plate (Fig. 3). Also, when survival was compared between tabular and arborescent species, there was no tendency for ASSs of tabular corals (A. digitifera and $A$. selago) to show higher survival rates than those of arborescent corals (A. muricata) in shallow water $(2.5 \mathrm{~m})$, whereas they showed lower survival in deeper water (5.5 or $11 \mathrm{~m}$ ). The absence of species-specific survival at the different depths suggests that this life stage of Acropora corals does not have an important role in forming the zonation.

Judging from the results of this study, the possibility still remains that the life stage from 6 months to 2 years after settlement is critical age in forming the zonation. So far, it was considered that strong wave mainly caused high mortality of arborescent corals in shallow waters. However, the distribution of recruits ( 2 weeks after settlement) was consistent with that of adult colonies at Tomino Reef (Suzuki et al. 2008). Consequently, selective settlement appears to be a more important factor than post-settlement mortality in establishing zonation in Acropora communities in Ishigaki.

\section{Factors affecting ASS mortality}

Among the different depths at Tomino Reef, higher mortality was recorded at $5.5 \mathrm{~m}$ than other depths within a month after settlement (Fig. 3). Although several environmental factors might have affected this high mortality, the main factor is thought to be a low intensity of light. There are three reasons. First, no sedimentation was observed at any depths in Tomino Reef (even on the upward-facing plates), second, some trails of predation by fish were found only on the upward-facing plate at all depths, and finally, direct cladding by other animals or algae that grow well in dark place was observed at all depths. At the $5.5 \mathrm{~m}$ depth, there were algal mats cultured by the damselfish Plectroglyphidodon lacrymatus, which mainly inhabits clumps of arborescent corals. It is considered that these algae shaded the light from the downward plates (Fig. 4B), and that the reduction of light decreased coral survival at this depth. This relationship may contribute to the dominance of arborescent corals by excluding larval recruitment. Because a large proportion of sexually recruited populations consists of tabular species at this site (Suzuki et al. 2008), the interruption of larval recruitment does more serious damage to tabular corals than arborescent ones. Coincidentally, the dominance of arborescent corals offers the advantage of increasing the habitat for damselfishes. To clarify whether the interruption of larval recruitment actually contributes to maintain a particular coral community or not, further researches are required.

\section{Acknowledgments}

This work was supported by the Experimental Research Budget for Conservation of the Global Environment, Ministry of the Environment, Japan. We thank A. Iguchi, K. Sakamoto, H. Shimizu, M. Tamaki, R. Fuseya and M. Katoh for help in the field research. We are also grateful to I. Hayashi, H. Fukami and Y. Shirayama for their valuable comments on the manuscript. The sampling of corals was exceptionally permitted by the Okinawa Prefectural Government for research use.

\section{References}

Adjeroud M (1997) Factors influencing spatial patterns on coral reefs around Moorea, French Polynesia. Mar Ecol Prog Ser 159: $105-119$

Babcock R, Mundy C (1996) Coral recruitment: Consequences of settlement choice for early growth and survivorship in two scleractinians. J Exp Mar Biol Ecol 206: 179-201

Baird AH, Babcock RC, Mundy CP (2003) Habitat selection by larvae influences the depth distribution of six common coral species. Mar Ecol Prog Ser 252: 289-293

Baird AH, Hughes TP (2000) Competitive dominance by tabular corals: an experimental analysis of recruitment and survival of understorey assemblages. J Exp Mar Biol Ecol 251: $117-132$

Bak RPM, Engel MS (1979) Distribution, abundance and survival of juvenile hermatypic corals (Scleractinia) and the importance of life histories strategies in the parent coral community. Mar Biol 54: 341-352

Done TJ (1982) Patterns in the distribution of coral communities across the central Great Barrier Reef. Coral Reefs 1: 95107 
Dunstan PK, Johnson CR (1998) Spatio-temporal variation in coral recruitment at different scales on Heron Reef, southern Great Barrier Reef. Coral Reefs 17: 71-81

Gosselin LA, Qian PY (1997) Juvenile mortality in benthic marine invertebrates. Mar Ecol Prog Ser 146: 265-282

Harrison PL, Wallace CC (1990) Reproduction, dispersal and recruitment of scleractinian corals. In: Dubinsky Z (ed) Ecosystem of the world, vol 25 Coral reefs. Elsevier, Amsterdam, pp 133-207

Hayashibara T, Iwao K, Omori M (2004a) Induction and control of spawning in Okinawan staghorn corals. Coral Reefs 23: 406-409

Hayashibara T, Shimizu H, Tamaki M, Nishihama S, Minagawa, M (2004b) Mass coral settlement on the artificial reefs in Ishigaki Island, Okinawa, Japan: evidence of sexual recruitment in the year following the 1998 bleaching event. Galaxea, JCRS 6: 47-51

Maida M, Coll JC, Sammarco PW (1994) Shedding new light on scleractinian coral recruitment. J Exp Mar Biol Ecol 180: 189-202

Mundy CN, Babcock RC (1998) Role of light intensity and spectral quality in coral settlement: Implications for depthdependent settlement? J Exp Mar Biol Ecol 223: 235-255

Mundy C, Babcock RC (2000) Are vertical distribution patterns of scleractinian corals maintained by pre- or post-settlement processes? A case study of three contrasting species. Mar Ecol Prog Ser 198: 109-119

Sato M (1985) Mortality and growth of juvenile coral Pocillopora damicornis (Linnaeus). Coral Reefs 4: 27-33

Sheppard CRC (1982) Coral populations on reef slopes and their major controls. Mar Ecol Prog Ser 7: 83-115

Suzuki G, Hayashibara T, Shirayama Y, Fukami H (2008) Evidence of species specific habitat selectivity of Acropora corals based on the identification of new recruits by two molecular markers. Mar Ecol Prog Ser 355: 149-159

Veron JEN (2000) Corals of the world. Australian Institute of Marine Science, Townsville, Australia

Wallace CC (1985) Reproduction, recruitment and fragmentation in nine sympatric species of the coral genus Acropora. Mar Biol 88: 217-233

Wallace CC (1999) Staghorn corals of the world. CSIRO Publishing, Collingwood, Australia

Wilson J, Harrison P (2005) Post-settlement mortality and growth of newly settled reef corals in a subtropical environment. Coral Reefs 24: 418-421

Received: 19 December 2008

Accepted: 31 May 2009

C Japanese Coral Reef Society 